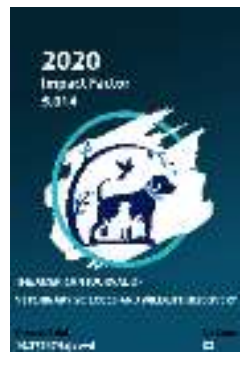

Journal Website: http://usajournalshub.c om/index,php/tajvswd

Copyright: Original content from this work may be used under the terms of the creative commons attributes 4.0 licence.

\section{Deficiency Of Vitamins A And D In Young Calves}

\author{
Nizom Farmonov \\ Candidate Of Veterinary Medicine, Associate Professor, Samarkand Institute Of Veterinary \\ Medicine, Uzbekistan \\ Joshqin Rejepbaev \\ Samarkand Institute Of Veterinary Medicine Nukus Branch Sitcom Researcher, Uzbekistan
}

\title{
ABSTRACT
}

This article provides data on the main cause of the disease in young animals - low intake of vitamin D in the body with nutrients and a decrease in its endogenous synthesis.

\section{KEYWORDS}

Vitamin D, rachitis, bone, carpal joints, laryngospasm, tonic tremor, asphyxia, bronchopneumonia, sepsis, trivitis, tetravitis, tetramag, multivit.

\section{INTRODUCTION}

As it is stated by Q.N. Norboyev and others (2007) in order to prevent lack of Vitamin D ration of pregnant cattle should be enriched with D2. In winter-spring period, due to the lack of such nutrients the diet is enriched with vitamin $\mathrm{D}$ supplements. Microgranulated preparations such as vitamin D3, microvit D3, prosol 500, lutovit D3 and dry yeast concentrates of vitamin $\mathrm{D}$ are added to do this. Two months before of inactivity, it is recommended to organize once-a-ten-day injections of such complex preparations as trivit, tetravit or tetramag. 
Pregnant cows and calves should undergo regular clinic examinations, with addressing the identified deficiencies and regulating the conditions of cattle housing and care. If necessary, it is recommended to give premixes and other additives containing food chalk, diammonium phosphate, tricalcium phosphate and vitamins. Ultraviolet lamps can be installed in the barns where young animals are kept.

According to Q.N. Norboyev and others (2007) in order to prevent lack of Vitamin D ration of pregnant cattle should be enriched with D2. In winter-spring period, due to the lack of such nutrients the diet is enriched with vitamin $D$ supplements. Microgranulated preparations such as vitamin D3, microvit D3, prosol 500, lutovit D3 and dry yeast concentrates of vitamin $\mathrm{D}$ are added to do this. Two months before of inactivity, it is recommended to organize once-a-ten-day injections of such complex preparations as trivit, tetravit or tetramag.

I.P. Ligomina recommends (2003) to use twice the "vitamin C complex+oligo" medicine with vitamins and amino acids in order to prevent microelements in pregnant cows. The influence of the drug results in improvement of saturation level of erythropoietin, hemoglobin synthesis and SRBC, as well as increase of serum protein and albumins, calcium and inorganic phosphorus and amount of vitamin A.
A. A. Skiba (2005), in his turn, recommends to use of a complex Profstimkor to prevent hypomicroelementosis in pregnant cows and newborn calves that are kept in rations missing a number of macro and micro minerals ( $\mathrm{Ca}, \mathrm{Fe}$, $\mathrm{Cu}, \mathrm{Zn}, \mathrm{K}, \mathrm{Na}$ ). If the drug is used 45 days prior to the birth of the cattle, it resulted in increase of macro- and micronutrients in the blood, erythrocytes, leukocyte and hemoglobin by 12 , 15 and 22.2 percent appropriately.

According to I.P. Kondrahin, V.I. Levchenko and others (2005), deficiency of vitamin A will cause young animals grow slower and difficult healing of sores. This is due to the slowing down of tissue regeneration processes. Animals" " $A$ " avitaminosis results in pathological changes in respiratory and digestive system, epithelium tissue of reproductive system, inflammation of mucous membranes of nose and eyes, xerophthalmia, ranging from clouding of eye cornea and hemeralopia.

A. A. Matsinovich (2005) states that the activity of vitamins in the body wis dependent on biological effects of micronutrients in many ways. Micronutrients play a great role in the collection and synthesis of vitamins in the body. If ration lacks such micronutrient as cobalt, copper, manganese it causes decrease of simbiotic flora activity of the gastrointestinal tract and, as a result, microbial the synthesis of vitamins is reduced.

As to A. Sidikov, I.Burlutskiy (1990), newborn animals with vitamin $A$ avitaminosis are weak and hypotrophic, with delayed standing pose and breastfeeding reflex. Because of lack of resistance to unfavorable environment and morphofunctional deficiency of digestive canal glandular's epithelium, lack of function of enzymes developed in animals, leading to disruption digestive processes. Animal will undergo general malaise, with malappetite, weight loss, slow growth, conjunctivitis, paleness of mouth and mucous membranes of the nose.

According to I. P. Kondrahin and V. I. Levchenko (2005), retinol deficit causes birth of blind piglets, with small weight, bad breastfeeding reflex and diarrhea. Piglets with A avitaminosis can have worsening eyesight with even loss of it. They have shudder, imbalance (ataxia) paralysis of the back legs. 
Sick animals may have slow growth and development, hypotrophy.

A. A. Skiba (2005), in his turn, recommends to use of a complex Profstimkor to prevent hypomicroelementosis in pregnant cows and newborn calves that are kept in rations missing a number of macro and micro minerals ( $\mathrm{Ca}, \mathrm{Fe}$, $\mathrm{Cu}, \mathrm{Zn}, \mathrm{K}, \mathrm{Na}$ ). If the drug is used 45 days prior to the birth of the cattle, it resulted in increase of macro- and micronutrients in the blood, erythrocytes, leukocyte and hemoglobin by 12, 15 and 22.2 percent appropriately.

Calves' D avitaminosis is characterized by violation of calcium and phosphorus circle in the organism, as well as malfunction of bone knitting process and deformation of chest bones.

The source of vitamin D2 for young calves is colostrum, milk and skim milk. Inadequate nutrition of pregnant cows, lack of active ration leads to a decrease of content of vitamin D2 in colostrum and milk they produce. In young calves, the body's failure to meet its vitamin needs leads to some diseases. Lack of phosphorus and other elements in the ration and excess of Strontium 90 in some radioactive zones is of certain etiological importance.

Vitamin D deficiency and lack of ultraviolet light are the main causes of decreased vitamin $D$ synthesis from 7-dehydrocholesterol disease. Such factors as violation of activity of prostate glands, actively involved in calcium metabolism in the body, lack or misbalance of calcium and phosphate salts, immense quantity of acidbase food in the ration and acid balance disruption due to digestive system disorders lead to rachitis at large.

Lack of cobalt in the body and marganese in couple with high level of iron and nickel lead to the development of endemic rachitis. Lack of vitamin $A$ and proteins exacerbates the development of the disease.

In young calves, rachitis is characterized by worsening of appetite, weight gain, impaired cognitive ability and Allotriophagia. Later, symptoms such as fatigue, strained movement, excessive lying down, limping, and pain in the joints and bones are observed.

Areas where bones grow most rapidly and the weight of the body is loaded most are deformed. Front legs are usually cross-legged, joints are warped or not fully bent. The amount of phosphoric acid and calcium salts in the bone marrow decreases sharply. Tubular bones in the forelegs and the spine are warped. Carpal joints swell, ribs bend inward, chest narrows laterally, thorax hangs down and increases in size.

Disorders of the nervous system, drowsiness or restlessness, laryngospasm, sudden fallings, short-term tremors or prolonged clonic and tonic tremors of body muscles are often observed during rachitis. Asphyxia can result in death of the cattle due to tremors of the muscles involved in breathing movements . The disease is often accompanied by symptoms of gastrointestinal catarrh, bronchopneumonia, fractures of certain bones, sepsis.

Treatment of young calves should be aimed at removing the deficit of vitamin $D$ and its active forms in the body and normalization of calcium-phosphorus metabolism disorders. Rachitis is often accompanied by diseases such as hypovitaminosis A, alimentary anemia. Therefore, retinol, iron, cobalt and other elements should be included in the treatment.

Vitamin D preservatives used according to prescriptions include oily solution of vitamin $D$ (0.125 - 0.5\%), alcoholic solution (0.5\%), water- 
soluble cholecalciferol-lipovide, trivit, tetravit, tetramag, multivit, fish oil. The medicines are given with food or parenterally for 10 - 15 days. The amount of vitamin D in them is taken into account when determining their dose. When given parenterally, the dose of cholecalciferol is $100-150 \mathrm{HB} / \mathrm{kg}$. When administered orally, it is $200-250 \mathrm{HB} / \mathrm{kg}$ for calves.

Pregnant animals' ration may be enriched with D2 vitamin-rich foods, whereas in winter-spring period, due to the lack of such food, ration is supplemented with vitamin D preparations.

When treating A avitaminosis, it is of great importance to ensure the enough amount of the vitamin in the food itself. Young animals' daily need for vitamin A is 250-300 HB for average of $1 \mathrm{~kg}$ of body weight. Respectively, demand for vitamin $A$ in case of sick animals increases for 2-5 times.

In case the amount of vitamin A in colostrum or milk does not satisfy the needs of a calf, the required preparations with 6-10 thousand $\mathrm{HB}$ should be given parenterally once a day. In these purposes, it is efficient to use trivit, tetravit, tetramag complex vitamins. In addition, retinol acetate solution of oil, axeroftol acetate and vitaminized fish oil can be used in accordance with presciption. Be taken into account in determining the structure of the dose of retinol ( $\mathrm{HB} /$ head): calves $50000-100000$, piglets and lambs 3000 - 10000, dogs 3000 - 40000. The course of treatment will continue an average of 15-20 days or more. A avitaminosis is treated along with near diseases.

Animals' need for carotene and vitamin A is met by feeding them substantially. For this purposes, mama animals and calves' ration should include vitamin nutrients, grass, greens, carrots, beer and seeds.
In case there are not enough vitamins in the diet, preparations are recommended. The prophylactic dose of vitamin $A$ is 4 times smaller than the therapeutic dose, and vitamin prophylaxis lasts 1-2 months.

In order to prevent hypovitaminosis $\mathrm{A}$ in calves , $10000-20000 \mathrm{HB}$ of retinol oil solution, aquital, trivit or other drugs are given in the first portion of colostrum, or for this purpose retinol oil concentrates is injected intramuscularly 1-2 times a week at a dose of 75000 - 125000 HB for calves, 40,000 - 50,000 HB for piglets and sheep. Antioxidants (diluidine, etc.) are used to protect the retinol in foods from spoilage.

Calves can receive enough dose of vitamin $A$ from colostrum during summer months. If a liter of milk contains $0,5 \mathrm{mg}$ retinol it is enough for calves. Within 15 days after birth, calves cannot make synthesis of retinol out of carotene. That's why, cows should be given a dose of 200-400 mg/kg carotene a day, when 1 mg carotene is equivalent to $533 \mathrm{HB}$ or $176 \mathrm{mg}$ retinol.

Preparations are recommended when there are not enough vitamins in the diet. The prophylactic dose of vitamin $A$ is 4 times smaller than the therapeutic dose, and vitamin prophylaxis lasts 1-2 months.

\section{REFERENCES}

1. Norboev Q. N., Bakirov B.B., Eshburiev B. M. Animals with infectious diseases. Textbook. Samarkand, 2007.

2. Ligomina I.P. Mechanism of vitamin A influence. / K.M. Leutskiy // III All-union biochemical congress. Riga: Zinatne, 2003. p. 254-256.

3. Skiba A.A. Avitaminosis and hypovitaminosis of hghly effective cattle / 
A.S. Solun // Moscow vetacademy publications. -M ., 2005 T. 7. - p. 110-119.

4. Kondrahin I.P., Levchenko V.I. Diagnosis and therapy of internal diseases of animals. Scientific publication. M.: Publishing house “Aquarium-Print" LLC 2005.

5. Matsinovich A.A., "Application of sodium hypochlorite in the complex of measures for the prevention of dyspepsia". Academy of Agrarian Sciences of the Republic of Belarus, 2005.

6. Sytdykov A., Burlutskiy I., Fledgling diseases. Tashkent. Labor. 1990.

7. Abramov C.S., Arestov I.G., Karput I. M. and others . Prevention of fledglings" NonCommunicable Diseases. - $M$. Agropromizdat. 1990.

8. Abramov S.S, Kovalenok Yu.K., Fetisov I.N. Veterinary and zootechnical problems in animal breeding. Mn. 1997.- - p. 58-60.

9. Bakirov B.B., Khabiev M.S. Fledglings' NonCommunicable Diseases. Samarkand , 1993. 